\title{
Decision tree analysis to evaluate dry cow strategies under UK conditions
}

Elizabeth A. Berry', Henk Hogeveen ${ }^{2}$ and J. Eric Hillerton ${ }^{1}$

${ }^{1}$ Institute for Animal Health, Compton, United Kingdom

${ }^{2}$ Department of Farm Animal Health, Utrecht University, the Netherlands

Economic decisions on animal health strategies address the cost benefit aspect atong with animal welfare and public health concerns. Using decision tree analysis at an individual cow level has highlighted that there is little economic difference between the use of either dry cow antibiotic or an internal teat sealant compared with no treatmnet in preventing a new intra mammary infection in a cow free of infection in all quarters of the mammary gland at drying off.

However, a potential net loss of over $\mathbf{2} 20$ per cow might occur if the uninfected cow was left untreated. The only economically viable option is antibiotic treatment, for a cow with one or more quarters infected at drying off, although a loss might still be incurred depending on the pathogen concerned and the cure rates achievable.

A net loss was found for cows with quarters infected with Corynebacterium spp. at drying off, for both the teat sealant and untreated groups ( $\mathrm{f} 22$ and $\mathrm{f} 48$ respectively) with only antibiotic treated cows showing a financial gain. Combinations of antibiotic of dry cow treatment and teat sealant are in increasingly common use based on enhanced prophylaxis. The cost benefit analysis of this combination suggests financial viability under certain circumstances. 